\title{
When a smile becomes a fist: the perception of facial and bodily expressions of emotion in violent offenders
}

\author{
M. E. Kret • B. de Gelder
}

Received: 29 January 2013 / Accepted: 1 May 2013 / Published online: 5 July 2013

(C) The Author(s) 2013. This article is published with open access at Springerlink.com

\begin{abstract}
Previous reports have suggested an enhancement of facial expression recognition in women as compared to men. It has also been suggested that men versus women have a greater attentional bias towards angry cues. Research has shown that facial expression recognition impairments and attentional biases towards anger are enhanced in violent criminal male offenders. Bodily expressions of anger form a more direct physical threat as compared to facial expressions. In four experiments, we tested how 29 imprisoned aggressive male offenders perceive body expressions by other males. The performance of all participants in a matching-to-sample task dropped significantly when the distracting image showed an angry posture. Violent offenders misjudged fearful body movements as expressing anger significantly more often than the control group. When violent offenders were asked to categorize facial expressions and ignore the simultaneously presented congruent or incongruent posture, they performed worse than the control group, specifically, when a smile was combined with an aggressive posture. Finally, violent offenders showed a greater congruency effect than controls when viewing postures as part of an emotionally congruent social scene and did not perform above chance when categorizing a happy posture presented in a fight scene. The results suggest that violent offenders have difficulties
\end{abstract}

\footnotetext{
M. E. Kret ( $\bowtie)$

Psychology Department, University of Amsterdam,

Weesperplein 4, Amsterdam, The Netherlands

e-mail: m.e.kret@uva.nl

B. de Gelder $(\square)$

Cognitive Neuroscience, Maastricht Brain Imaging Centre

M-BIC, Maastricht University, Oxfordlaan 55, 6229

ER Maastricht, The Netherlands

e-mail: B.deGelder@maastrichtuniversity.nl
}

in processing emotional incongruence when aggressive stimuli are involved and a possible bias towards aggressive body language.

Keywords Aggression - Violent offenders · Body language $\cdot$ Context $\cdot$ Attention $\cdot$ Emotion attribution

\section{Introduction}

Emotional cues shown in the face and body serve as crucial regulators of social behaviour (Frijda 1986; de Gelder 2006). For example, expressions of anger represent an immediate threat to one's safety. Emotional expressions are readily detected, and they prompt quick responses in the observer (Becker et al. 2007; Fox et al. 2000; Schupp et al. 2004; Bannerman et al. 2009). But the perception of and the responsiveness to aggressive cues may vary with gender and with personal history. Threat is detected particularly well when expressed by men (Becker et al. 2007; Zebrowitz et al. 2010; Öhman and Dimberg 1978; Marinkovic and Halgren 1998). Impaired recognition and misinterpretation of facial expressions as signs of threat have been observed in male offenders (Gery et al. 2009; Hoaken et al. 2007; McCown et al. 1986; Sato et al. 2009), a group with high exposure to aggression from an early age (Lansford et al. 1995). Moreover, Mazurski et al. (1996) observed an enhanced electrodermal response in men only during exposure to angry male faces. This would suggest that this perceptual bias is linked to male-male aggressive challenges (i.e., fight mode).

Studies using aggressive offenders have made the link between aggression and impaired recognition of facial expressions. But the aggressive menace is clearer when the angry face is accompanied by whole body signals. This 
is shown by the fact that viewing body expressions triggers activity in action preparation areas (de Gelder et al. 2004; Grèzes et al. 2007). Kret et al. (2011) observed that men, as compared to women, showed higher activation of motor preparation areas when they observed threatening male versus female body expressions. Following this line of reasoning, we predicted that aggressive men are even more sensitive to the threatening cues of other men. We investigated this hypothesis in a highly aggressive group of offenders selected based on the type of crime they committed (aggressive offence towards a male victim), on their trajectory of recidivism of similar offences and on their aggressive behaviour in prison. In four experiments, we tested whether violent offenders can (1) match emotions in static postures, (2) recognize emotions from dynamic bodies, (3) recognize facial expressions when the body expression is emotionally incongruent and (4) recognize bodily expressions when the social context is emotionally incongruent.

A general emotion recognition impairment in violent offenders was not predicted. However, we expected to find group differences in the implicit effects of aggressive body language. More specifically, in Experiment 1, we expected a stimulus gender effect in the sense that the presence of angry male signals would interfere more with matching performance in the violent offender group than angry female signals or other emotional expressions. We expected a similar pattern in the control group (men would be distracted most by angry male body language), but a more pronounced effect in the offenders. Based on previous studies that showed that men, and especially aggressive men, interpret others' intentions as hostile (Sancilio et al. 1989; Waas 1988), in Experiment 2, we expected differences in the error rates, in that, the offender group would more often than the control group recognize dynamic bodily expressions of emotion as being angry. Our final hypothesis was that the performance of the offender group would suffer from an emotionally incongruent context, especially when the distracting context showed aggression (a body and scene context in experiment 3 and 4, respectively).

\section{Methods}

\section{Participants}

Twenty-nine violent incarcerated male offenders participated. They were incarcerated in three Dutch prisons, $\mathrm{Z}$ $(N=11), \mathrm{K}(N=11), \mathrm{D}(N=7)$, and convicted for armed robbery with aggravated assault causing bodily harm, threats and violence $(N=16)$ or homicide $(N=13)$. Their average age was young (mean age: 31.65 years, range 19-61 years old); yet, ten individuals had been convicted before for similar crimes, on average on 4.50 (SD 2.41) occasions. All crimes for which the participants were convicted at the time of testing were directed towards another adult man. They were imprisoned for 2.78 years (SD 2.79) ranging from 4 months to 12.22 years and were convicted for 4.65 years (SD 3.80) ranging from 6 months to 15.75 years. Our aim was to test the most aggressive offenders: those who most often got into fights with other men, who were perceived as aggressive by the staff and who had a history of recidivism outside prison. To locate such offenders, a list of candidates was made by the research department of the Headquarter of the Dutch Judicial Service Commission based on specific articles of law, including articles about criminal charges for violent offences against persons-for example, assault causing bodily harm, wounding, attempted homicide, homicide, armed robbery with aggravated assaults, threats and extreme violence. The list was shortened to exclude people older than 65 and people from the psychopathy department. We approached the psychologists, social workers and guards and selected the candidates from among this list which they thought were most suitable based on (1) number of recidivisms, (2) aggressive behaviour in prison and (3) health. ${ }^{1}$ Half of the offenders who were approached agreed to participate. Six out of twenty-nine offenders indicated to have sought psychological treatment: three for aggression regulation problems, two for depression (one was on medication), two for stress and one for fatigue, as assessed with a 15-item questionnaire that included questions about past and present medical and psychological problems.

The control group consisted of 31 males matched on age (mean age 32.31 years, range 18-62 years old). The control group consisted of similar nationalities as the offender group and included uneducated and unemployed men. The controls were recruited from the technical and maintenance staff of the university, via advertisements in community centres, an integration course for ethnic minorities, and a reintegration course for unemployed people. Exclusion criteria included a neurological or psychiatric history or a criminal record. See Table 1 for details. All participants received a small financial compensation. The study was conducted in accordance with the ethical provisions of the institutes and the Declaration of Helsinki.

\footnotetext{
1 We discussed all these characteristics of the candidates in great detail. In order to select the most aggressive offenders, we looked at their history of recidivisms (data were available from 1996 onwards) and the number of times they got into fights with other prisoners (after which they were put in the isolation cell, which is always recorded). But we also discussed their health, their current situation and whether it would be practically possible at all to test certain subjects. After that, we approached these people and asked whether they would like to participate.
} 
Table 1 Participants

\begin{tabular}{|c|c|c|}
\hline & Violent offender group & Control group \\
\hline Nationalities & $\begin{array}{l}\text { Dominican Republic, Iraq, Israel, } 3 \times \text { Morocco, } \\
3 \times \text { Netherlands Antilles, Pakistan, Republic } \\
\text { of Cape Verde, } 4 \times \text { Republic of Surinam, Serbia, } \\
7 \times \text { The Netherlands, Trinidad and Tobago, } \\
3 \times \text { Turkey, Yugoslavia }\end{array}$ & $\begin{array}{l}\text { Armenia, Belgium, } 2 \times \text { Canada, France, } \\
\text { Germany, } 4 \times \text { Indonesia, } 2 \times \text { Iraq, Ireland, } \\
\text { Nepal, Republic of Cape Verde, } 2 \times \text { Republic } \\
\text { of Surinam, Serbia, } 9 \times \text { The Netherlands, } \\
4 \times \text { Turkey }\end{array}$ \\
\hline \multirow[t]{7}{*}{ Education and work } & 3 only finished primary school & 1 only finished primary school \\
\hline & 11 only finished high school & 2 only finished high school \\
\hline & 11 finished MBO & 10 finished MBO \\
\hline & 1 finished WO & 8 finished $\mathrm{HBO}$ \\
\hline & 8 had to quit their study but might continue & 2 finished WO \\
\hline & 6 were studying at $\mathrm{MBO}$ level in prison & 4 studying at $\mathrm{HBO} / \mathrm{WO}$ level \\
\hline & 26 worked in prison & 5 unemployed \\
\hline Mean age & 31.65 years, range $19-61$ years old & 32.31 years, range $18-62$ years old \\
\hline
\end{tabular}

In the Netherlands, the highest finished education of the male population was at the time of testing about $10 \%$ primary school, $50 \%$ high school, $20 \%$ bachelor degree, $15 \%$ master degree. Of those, $4 \%$ was unemployed

$\mathrm{WO}=$ Masters' degree at science university. Can only be entered after 6 years of highest level high school

$\mathrm{HBO}=$ Bachelors' degree at non-science university. Can be entered after 5 years of medium level high school

$\mathrm{MBO}=2-3$ year practical school which starts after 4 years of lowest level high school

\section{Materials and procedure}

The experiments were administered in consulting rooms in the prisons and at Tilburg University. The experimenter was present in the experimental room with the participant without the presence of any another person. The testing situation for the control group was kept as similar as possible (i.e., the experiments in both groups ran intermixed in the same months, the same equipment was used and the same test-leader was present during the task. The test-leader always followed a typed-out protocol). The experiment ran on Presentation software (Neurobehavioral Systems, San Francisco, CA), implemented on a laptop (Latitude E5500, Dell) with a $60 \mathrm{~Hz}$ refresh rate. Distance to the computer screen was $60 \mathrm{~cm}$. The order of the experiments and the labels on the response box was counterbalanced. Instructions were given in Dutch, English, French or Turkish. Each experiment included five practice trials, and the procedure was repeated when an error was made.

\section{Experiment 1: Matching bodily expressions}

Materials and procedure

A matching task was used to investigate how emotions were recognized without the use of verbal labels. The task was to indicate whether the left or right posture presented at the bottom of the screen showed the same expression as the top one. No time limits were set, and no feedback was provided, except during the test trials. Three different same-sex actors were shown per trial. Materials consisted of 72 grey-scale photographs representing angry, fearful, happy and sad postures with the face blurred (310 pixels in height). We included images of 24 actors (half males and half females) that were correctly recognized above $70 \%$ in a validation study (de Gelder and van den Stock 2011).

\section{Data analysis}

Main and interaction effects of accuracy were tested in a generalized mixed multilevel model with the following fixed factors: Group (offender or control): Target expression (four emotions), Distractor expression (four emotions), Sex (male or female actor), Group * Sex, Group * Target expression, Group * Distractor expression, Target expression * Sex, Distractor expression * Sex, Group * Target expression * Sex and Group * Distractor expression * Sex. A random intercept was included, as well as a random intercept for each trial. This allowed each trial to have its own intercept across participants, in addition to the random intercept per participant. The benefit of analysing the data in a multilevel model is that data are never averaged over conditions, that is, all individual trials, nested within subjects, are included in the model, and consequently, the variance within individuals is maintained. This is especially recommended when the subject group is quite heterogeneous (which is for example often the case in patient studies). In addition, this type of analysis allowed us to choose a binary distribution for our dependent variable that was coded as 0 (incorrect) and 1 (correct). The goal of this analysis is not to search for specific effects, but to end up with a model that best fits the 
data. In other words, to have a final model in which the variance is explained most optimally. It is common to start with a full model and drop non-significant factors one by one, starting with the higher-order interactions (Garson 2012).

Results

There were significant main effects for target emotion $F(3$, $1.421)=13.869, p<.001$, and distracting emotion $F(3$, $1,421)=21.165, p<.001$, an interaction between target and sex of the actor $F(3,1.421)=3.734, p=.011$, and marginally significant interactions between sex of the actor and distractor $F(3,1.421)=2.103, p=.081$, and group * target $F(3,1.421)=2.160, p=.091$. Sad postures were most accurately recognized (mean $=99 \%$, $\mathrm{SE}=0.4)$, followed by happy (mean $=94 \%, \mathrm{SE}=1.3$ ), fearful (mean $=91 \%, \mathrm{SE}=2.0$ ) and angry expressions $($ mean $=86 \%, \mathrm{SE}=2.7)$. Angry postures were somewhat better recognized from a male versus female actor (mean $=90 \%, \mathrm{SE}=3.0$ vs. mean $=82 \%, \mathrm{SE}=4.1$, $p=.099)$, and fearful postures were better recognized from a female versus male actor ( mean $=95 \%, \mathrm{SE}=1.80$ vs. mean $=84 \%, \mathrm{SE}=3.5, p=.001)$. Accuracy was lowest when the distracting posture expressed anger
$($ mean $=82 \%, \mathrm{SE}=3.1)$ versus fear $($ mean $=93 \%$, $\mathrm{SE}=1.7)$, happy $($ mean $=97 \%, \mathrm{SE}=1.0)$, sad $($ mean $=99 \%, \mathrm{SE}=.5)$ and $p$ values $<.001$. Angry and happy postures were somewhat more distracting when the actor was male versus female $(p=.099$ and $p=.021)$. Follow-up comparisons of the interaction group $*$ target did not reveal any significant effects.

A confirmation of our hypothesis (that violent offenders' performance would drop when the distracting picture showed an aggressive male) would have required a significant three-way interaction between Group * Distractor expression $*$ Sex. However, this interaction was not significant $F(3,1.421)=2.249, p=.20$, because the control group showed a similar pattern and was mostly distracted by angry male postures. See Fig. 1.

\section{Conclusion}

In both groups, performance was lowest by the presence of a distracting angry male body. We would have expected this effect to be somewhat larger in the violent offender versus control group, but although numerically consistent with our hypothesis, this was not confirmed statistically. Men from both groups were distracted
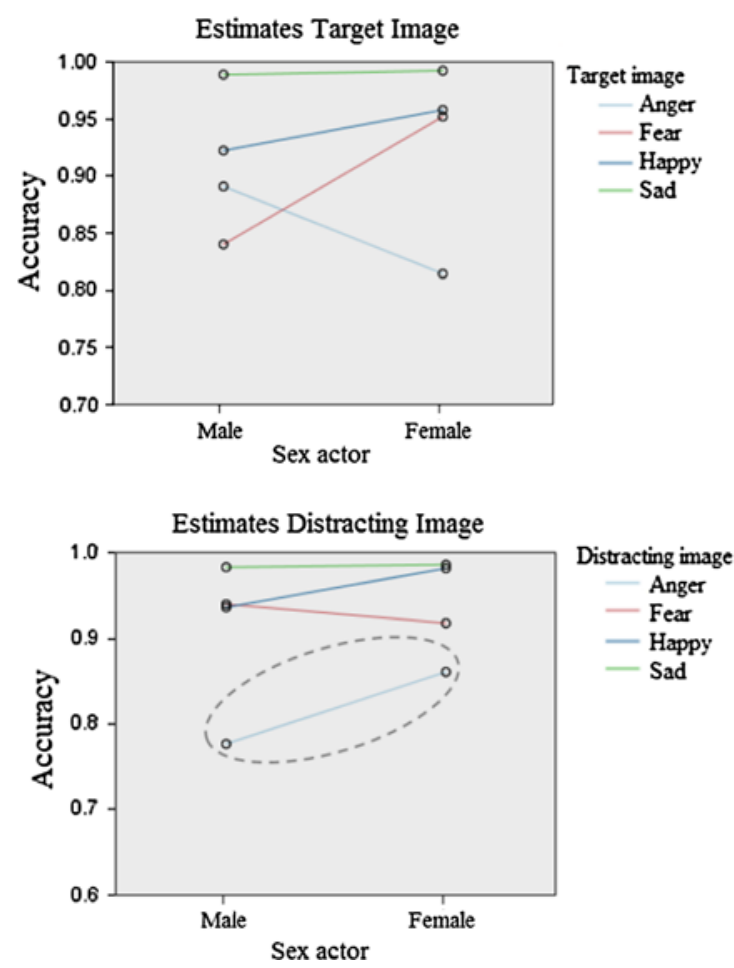

Angy, distracting body posture

Estimates angry, distracting body posture

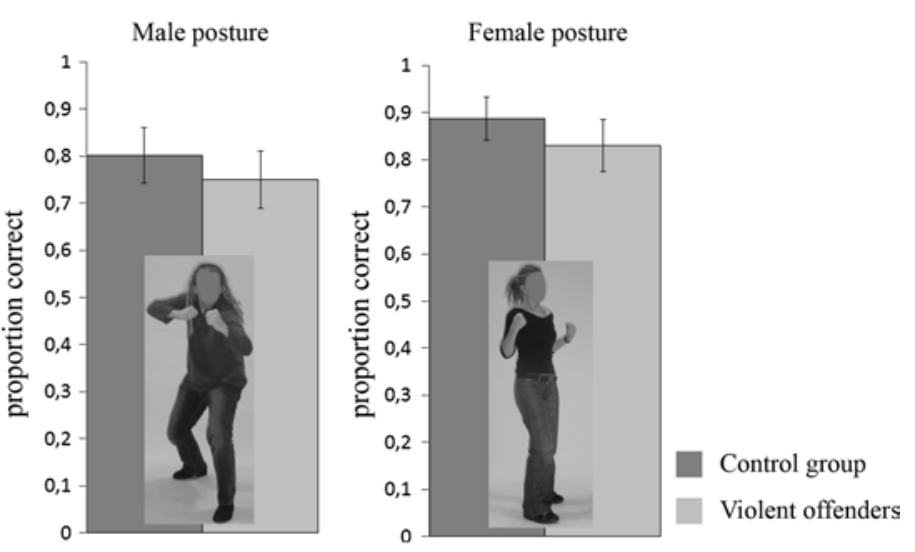

Fig. 1 Matching to sample task. The line-graphs show the data from all participants. The light blue line within the dotted circle shows the accuracy when the distracting image was an angry posture. Both groups were mostly distracted by angry, male postures which can be seen for both groups separately in the bar graphs 
mostly by threatening male body postures. Angry male postures attracted the attention and possibly triggered an approach response. This explanation would be in line with a recent study that actually showed that psychopathic offenders lacked the automatic avoidance of angry facial expressions. Interestingly, the lack of avoidance responses was related to levels of instrumental aggression and probably not specific for psychopaths but generalizable to other aggressive populations (von Borries et al. 2012). Another bias which has been reported in aggressive populations is the hostile attribution bias, that is, a tendency to see situations as threatening (Dodge et al. 1990). In Experiment 2, we investigate whether this bias extends to bodily movements.

\section{Experiment 2: Dynamic bodily expression of emotion}

Materials and procedure

Two-second video clips of bodily expressions that were recognized above $90 \%$ correct by Tilburg University students were selected from among our own validated stimulus database (Kret et al. 2011). We selected angry, fearful and happy bodily expressions from 10 male actors. Participants were instructed to categorize the emotion and choose among four options: anger, fear, happy or neutral. Neutral was included as response option to not restrain participants to choices limited to the target emotions (Hastings et al. 2008). At the end of a video, a blank screen with a question mark appeared. Once a participant responded, a blank screen appeared for 2-3 s after which a fixation cross was presented.

\section{Data analysis}

Main and interaction effects for accuracy were tested in a generalized mixed multilevel model with 'body expression' (anger, fear or happy) and 'group' (offender or control) as fixed factors. A random intercept was included for each participant, as well as a random intercept for each trial. As in Experiment 1, the dependent variable was binary and we did not average trials over conditions. We also tested whether the two groups differed in the specific errors they made.

\section{Results}

The interaction between group and emotion $[F(2$, $4.428)=8.554, p<.001]$ showed that offenders were worse than controls in recognizing fear (Mean $=86 \%$, $\mathrm{SE}=2.0$ vs. Mean $=92 \%, \mathrm{SE}=1.3, p<.01)$. There was a main effect of emotion: Angry expressions were recognized less accurately than fear and happiness $[F(2$, $4.428)=33.947, p<.001]$. Both groups made more anger versus happy or fear misclassifications $(p<.001)$, but the offenders showed a stronger bias which was significantly different from the control group for fearful movements. These were more often than the control group interpreted as angry $[F(1,1.195)=4.351, p<.05]$ but not as happy $(p=.450)$. In addition, the groups did not differ in recognizing happy expressions as angry $(p=.372)$ or fearful $(p=.979)$, anger as fearful $(p=.983)$ or happy $(p=.916)$. See Fig. 2.

As predicted, violent offenders were worse than controls in recognizing fear from body movements and misinterpreted this emotion as anger. This result is partly in line with Sato et al. (2009). In that study, three additional emotional expression categories were used including disgust. They observed that offenders misjudged disgusted (but not fearful) faces as angry more often than controls. The different results in that study and the current study may be due to methodological differences. An alternative interpretation for the anger-interpretation bias that offenders seem to have is that violent offenders are less sensitive to fearful movements than the control group.

In a naturalistic situation, emotions are expressed dynamically, with the body and the face, and in a valid context in which other people are often present. By manipulating these characteristics one by one rather than all at once [i.e., the dynamics (Experiment 2), the face context (Experiment 3) and the scene context (Experiment 4)], we will get more insight into which factors contribute to misrecognitions and attentional biases. As we just mentioned, in real life, one sees the face combined with a body which influences how the face is perceived (Meeren et al. 2005). The next experiment tests whether violent offenders have a deficit in categorizing a facial expression in the context of a threatening male body expression. The body context is manipulated and either shows the same or a different expression as the face.

\section{Experiment 3: Facial expression recognition with congruent or incongruent body expression}

\section{Materials and procedure}

Face-body compound images were created by pasting emotionally congruent or incongruent body expressions below emotional faces of eight new male actors. The validation of these stimuli is described in Kret et al. (2013). The stimuli were briefly $(100 \mathrm{~ms})$ presented to avoid ceiling effects and to provide space for the interference of body expressions (Kret and de Gelder 2010, 2012). The same emotions were 

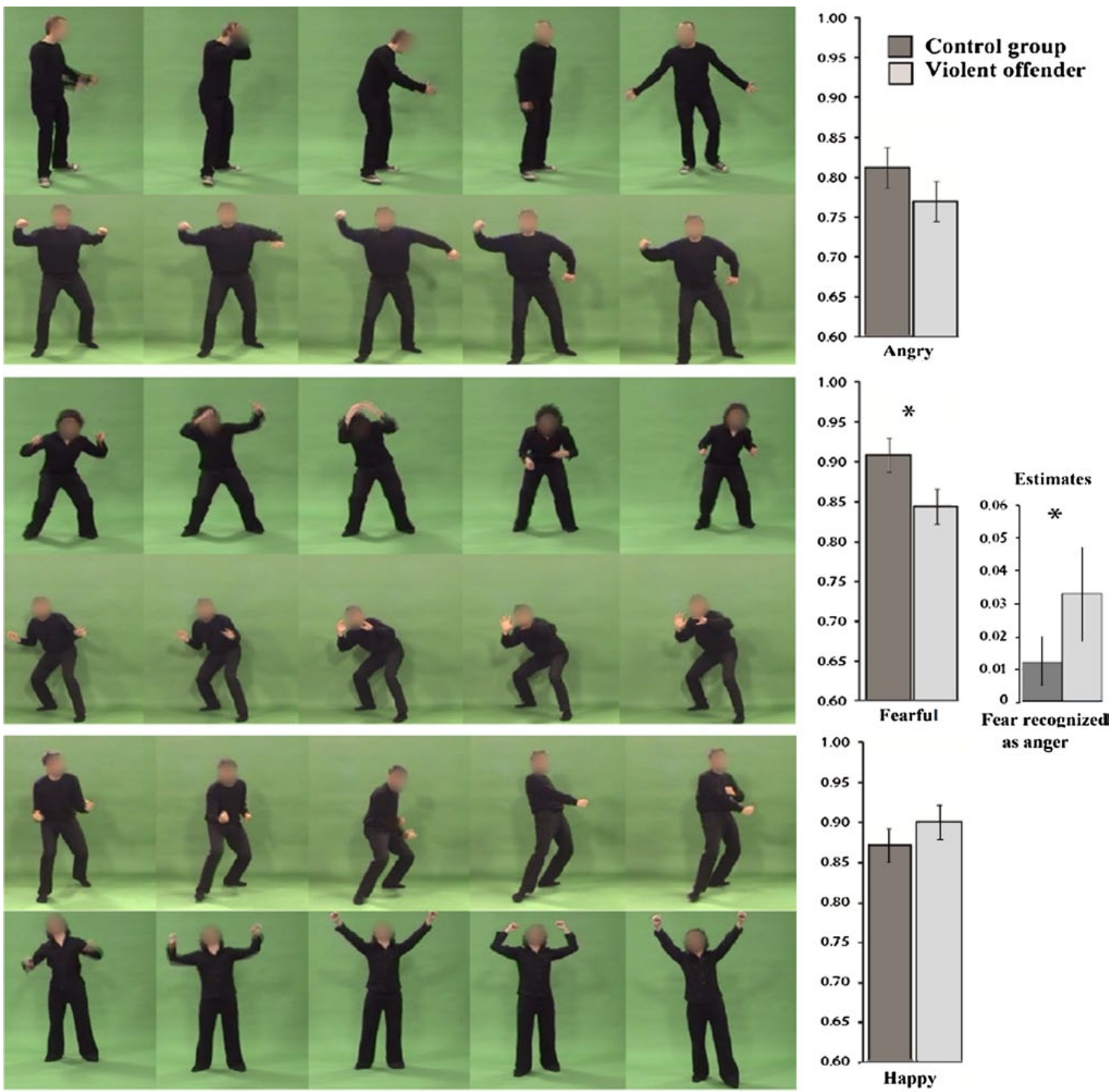

as anger

\section{2 second video}

Fig. 2 Recognition rates of dynamic bodily expressions of emotion. Different stimulus exemplars. Violent offenders were worse in recognizing fear than the control group and recognized this emotion as anger more often than the control group. * $p<.05$

used as in Experiment 2. Participants were asked to categorize the facial expression and ignore the body. After a response, a grey screen appeared on which after $5,700 \mathrm{~ms}$, a fixation cross was presented for $300 \mathrm{~ms}$. In total, 72 pictures were shown ( 3 facial expressions $* 3$ postures * 8 actors). We predicted that violent offenders would be impaired in recognizing a happy or fearful face when an angry posture was presented simultaneously.

\section{Data analysis}

Main and interaction effects of group and emotion on accuracy and reaction time were tested in a generalized mixed model with the following fixed predictors: 'facial expression' (3: anger, happy, fear) and 'bodily expression' (3: angry, happy and fearful postures) and 'group' (2: offender or control). Only the reaction times on correct 
trials were analysed. In addition, reaction times above $4,000 \mathrm{~ms}$ were not included in the analysis $(0.83 \%)$. A random intercept was included, as well as a random intercept for each trial.

Results

\section{Accuracy}

Generally, faces were better recognized when paired with a congruent vs. incongruent posture $([F(2,4.297)=36.277$, $p<.001]$ all comparisons $p$ values $<.001)$. There was an interaction between group, emotion of the face and body posture $[F(4,4.291)=6.988, p<.0001]$. Offenders were less accurate than controls $[F(1,4.291)=12.133$, $p<.005]$. However, the three-way interaction shows that offenders were not always less accurate than the control group. As expected, violent offenders differed mostly from the control group when happy faces were accompanied with angry bodies $(p<.001)$. In addition, they were worse than controls when categorizing happy faces with happy bodies and angry faces with happy and fearful bodies ( $p$ values $<.005)$. There were some additional effects that would not survive a Bonferroni correction: Violent offenders were worse in recognizing a happy face above a fearful body $(p=.029)$ and were somewhat better than the control group in recognizing fearful faces paired with angry bodies $(p=.035)$. To test whether the major and statistically most significant result that happy faces with angry bodies were particularly difficult to recognize for the offender group, not just due to the incongruence between the two emotional signals, but due to the angry body posture, we calculated a difference score between happy faces paired with angry minus fearful bodies and compared both groups. This yielded a significant difference between the two groups $(p=.01)$. In addition, within the offender group, accuracy was lower when happy faces were paired with angry versus fearful bodies $(p<.001)$. See Fig. 3 and Table 2.

\section{Reaction time}

There was a significant interaction between group, emotion of the face and body posture $[F(2,2.864)=3.750$, $p<.001]$. There were main effects for bodily expression $[F(1,2.864)=9.813, p<.0001]$ and for facial expression $[F(2,2.864)=51.840, p<.001]$. Both groups recognized the three facial expressions faster when paired with a body that expressed the same versus a different emotion (all $p$ s < .001). Most interestingly, violent offenders were slower than the control group in categorizing happy faces when paired with angry postures $(p=.013)$. The two groups did not differ in any other condition $(p>.152)$. See Fig. 3 and Table 2.

\section{Conclusion}

As predicted, violent offenders were impaired in categorizing a happy face when the posture expressed aggression. In the final experiment, we investigated whether the recognition of a happy posture is influenced by the social scene and more strongly in violent offenders than in controls.

\section{Experiment 4: Bodily expression recognition in congruent or incongruent social scenes}

Eight happy and angry postures from the same set as previously described were included. Angry (fight), happy (party) and neutral (sports) scenes were selected from the Internet
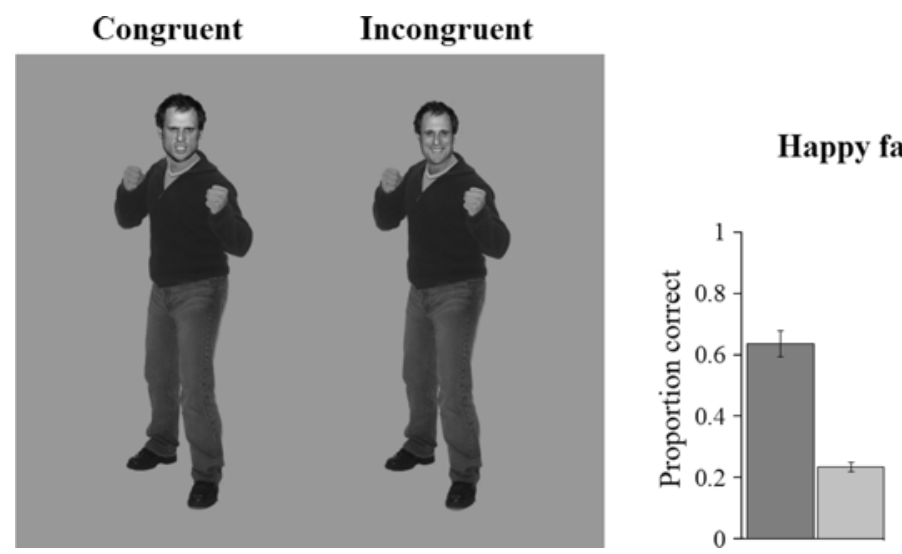

Happy face, angry posture

Fig. 3 Emotionally congruent and incongruent face-body compounds. Violent offenders were worse than the participants in the control group in recognizing a happy face when the body expressed anger and the performance in this condition was lower than in any other condition 
Table 2 Significant differences between the two groups are printed in bold

\begin{tabular}{|c|c|c|c|c|c|c|c|c|c|}
\hline \multirow{2}{*}{\multicolumn{2}{|c|}{ Expression }} & \multicolumn{4}{|c|}{ Control group } & \multicolumn{4}{|c|}{ Violent offenders } \\
\hline & & \multicolumn{2}{|c|}{ Reaction time } & \multicolumn{2}{|l|}{ Accuracy } & \multicolumn{2}{|c|}{ Reaction time } & \multicolumn{2}{|c|}{ Accuracy } \\
\hline Face & Body & Mean & SE & Mean & SE & Mean & SE & Mean & SE \\
\hline \multirow[t]{3}{*}{ Anger } & Anger & $1,055.96$ & 50.43 & 0.93 & 0.02 & $1,070.23$ & 52.39 & 0.90 & 0.02 \\
\hline & Fear & $1,335.40$ & 63.21 & $0.43 * * * *$ & 0.05 & $1,270.90$ & 89.58 & 0.14 & 0.03 \\
\hline & Happy & $1,358.74$ & 57.43 & $\mathbf{0 . 5 9} * * * *$ & 0.05 & $1,495.84$ & 76.64 & 0.19 & 0.04 \\
\hline \multirow[t]{3}{*}{ Fear } & Anger & $1,290.47$ & 68.26 & $0.44 *$ & 0.06 & $1,108.27$ & 65.36 & 0.61 & 0.06 \\
\hline & Fear & $1,036.18$ & 50.75 & 0.88 & 0.02 & $1,038.79$ & 52.54 & 0.88 & 0.02 \\
\hline & Happy & $1,253.37$ & 55.75 & 0.79 & 0.04 & $1,217.57$ & 58.96 & 0.70 & 0.05 \\
\hline \multirow[t]{3}{*}{ Happy } & Anger & $834.15 *$ & 56.78 & $0.64 * * * *$ & 0.05 & $1,065.44$ & 73.12 & 0.23 & 0.04 \\
\hline & Fear & $1,048.49$ & 95.57 & $0.84 *$ & 0.07 & 972.66 & 115.54 & 0.56 & 0.10 \\
\hline & Happy & 810.19 & 50.46 & $0.92 * * *$ & 0.02 & 890.22 & 53.03 & 0.81 & 0.03 \\
\hline
\end{tabular}

The most significant difference between the offender and control group is found in the condition where happy faces were paired with an aggressive posture (third row from below)

$* \mathrm{p}<.05$

$* * \mathrm{p}<.01$

$* * * \mathrm{p}<.005$

$* * * * \mathrm{p}<.001$

[for details see Kret and de Gelder (2010)]. We conducted an additional validation study among 36 students who rated the scenes on intensity and arousal. Neutral scenes were rated as significantly calmer than happy scenes $t(35)$ $=4.098, p<.001$ and as somewhat calmer than angry scenes $t(35)=1.836, p=.075$. Angry and happy scenes were equally emotionally intense $t(35)=.462, p=.647$ and were both more intense than neutral scenes $t(35)=$ $4.298, p<.001 ; t(35)=7.109, p<.001$. Emotionally congruent or incongruent postures were placed in the scenes. Participants were given a two-alternative forced choice task and were instructed to focus on the main figure, ignore the scene and categorize the body emotion. A trial started with a fixation cross on a grey screen (300 ms), a stimulus (100 ms), followed by a grey screen shown until button press.

\section{Data analysis}

Effects of bodily expression recognition accuracy in congruent or incongruent scenes and reaction times were tested in a generalized mixed multilevel model with 'body expression' (anger or happy), 'scene emotion' (anger, neutral, happy) and 'group' (offender or control) as fixed factors. A random intercept was included, as well as a random intercept for each trial. The distribution was binary for the accuracy measure and linear for the analysis of reaction times. Due to strict time schedule regulations, the data of one offender could not be collected, as he had to return to his cell.
Results

\section{Accuracy}

There was an interaction between group, emotion of the scene and body expression $[F(2,5.227)=19.454, p<.001]$ supported by two-way interactions between body expression $*$ scene emotion $[F(2,5.227)=134.849, p<.001]$ and group $*$ body expression $[F(1,5.227)=6.688, p<.01]$ and a main effect of body expression $[F(1,5.227)=62.392$, $p<.001]$. Both groups showed a congruency effect ( $p$ values $<.05)$, but interestingly, this effect seemed stronger in the offenders. To confirm this statistically, we ran an analysis on the difference scores between the recognition of happy bodies in a happy minus angry scene and angry bodies in an angry minus happy scene and found a main effect of group $[F(1,232)=4.947, p<.05]$. In addition, violent offenders also showed a difference between the congruent conditions and the neutral context condition, whereas the control group did not [happy postures in happy context and angry postures in angry vs. neutral context, $(p s<.005)]$. When categorizing happy postures in an angry context, violent offenders were not different from chance $(p=.992)$. However, the control group was not better than chance either ( $p=.113)$, and the two groups did not significantly differ in this condition $(p=.159)$, which might be due to a floor effect. The greater congruency effect for happy bodies in the offender group was also explained by the fact that they were somewhat better in recognizing happy bodies in a happy scene than the control group $(p<.05)$. See Fig. 4. 

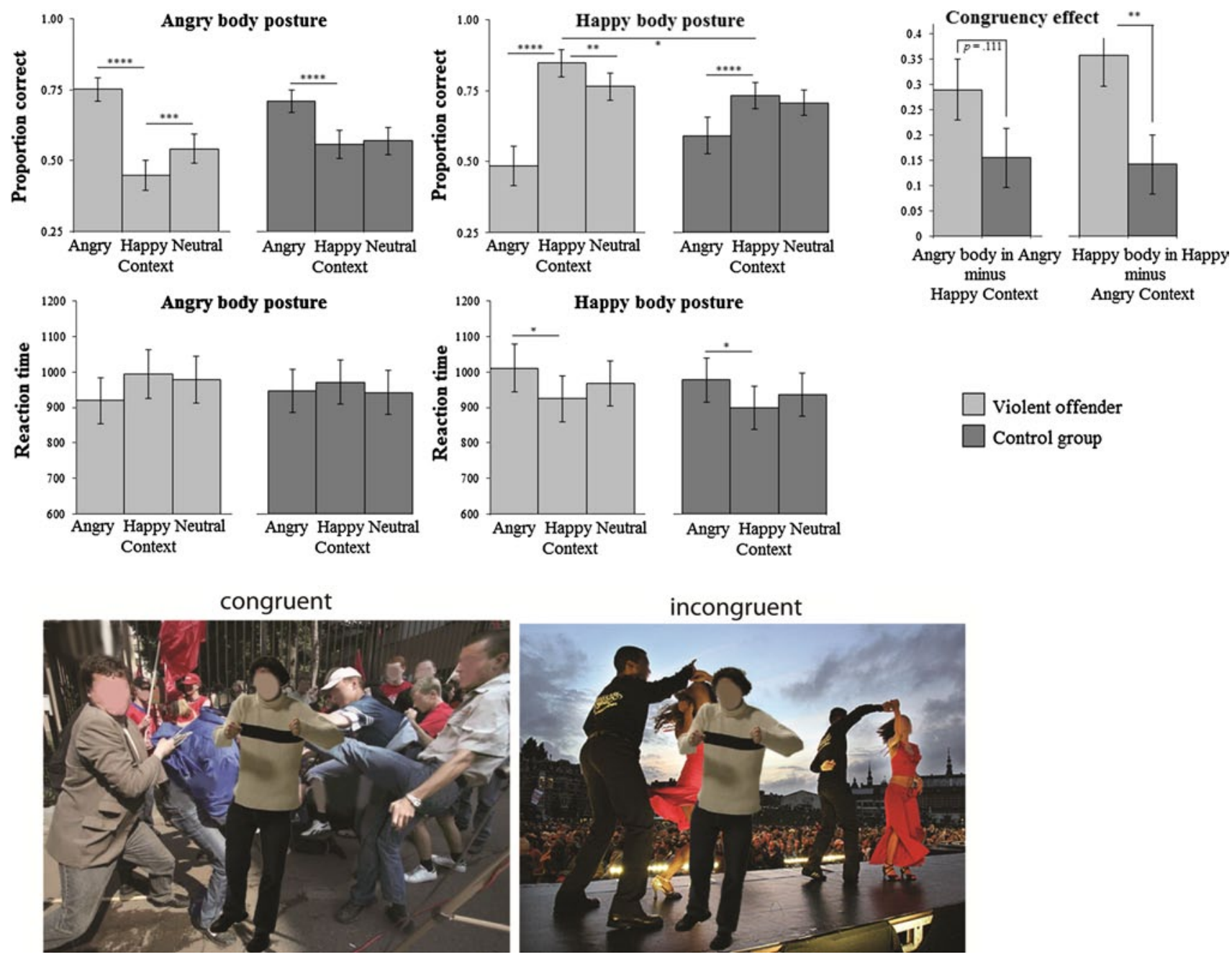

Fig. 4 Recognition of body expressions in congruent and incongruent social scenes. Both groups, but especially the violent offenders, were better in recognizing body postures when these were placed in a congruent versus incongruent context. Violent offenders in particular were impaired in recognizing happy body postures when a fight was presented in the background

\section{Reaction times}

There was an interaction between body and scene emotion $[F(2,3.330)=6.048, p<.005]$. Reaction times for angry bodies were shortest when presented in an angry scene $(p$ values <.01). See Fig. 4.

\section{Conclusion}

The results are partly in line with our hypothesis. As predicted, violent offenders could not recognize happy body expressions when a fight was presented simultaneously. However, the control group also faced great difficulties in this condition, and although the effect is amplified in the offender group, it may actually be more generalizable to men in general, like the findings of Experiment 1.

\section{Discussion}

In a situation where aggressive body language contrasts with a smiling face or where a happy posture seems out of place in an aggressive scene, violent offenders' behaviour is influenced disproportionally by the presence of threat signals. The four experiments are consistent in their results. First, both violent offenders and the control group were impaired in matching postures when the distracter image was an aggressive male posture. Second, violent offenders tended to misjudge fearful body movements as aggressive more often than the control group. Third, violent offenders were impaired in recognizing a happy face when simultaneously presented as part of an aggressive posture. Fourth, violent offenders and control participants were impaired in recognizing a happy posture when viewed against the background of a violent scene. 
Previous studies have shown a deficit in facial expression recognition in aggressive offenders (Gery et al. 2009; Hoaken et al. 2007; McCown et al. 1986; Sato et al. 2009) and psychopaths (Marsh and Blair 2008). Our study adds to this research by showing strong responses towards aggressive postures, a direct physically threatening stimulus. Moreover, consistent with the literature on aggression in the male population, enhanced effects were observed for male body expressions. This result is not due to impaired body expression recognition. Overall, violent offenders performed similar to the control group; they could match body expressions, correctly identify emotional body movements and recognize postures in a congruent or neutral context. Difficulties arose where multiple emotional cues were present, and particularly when threatening postures had to be ignored. In line with our previous studies in healthy populations, we found in Experiment 3 that facial expressions were better recognized when accompanied by a body that expressed the same emotion (Meeren et al. 2005). Similarly, in Experiment 4, we observed that body expressions were best recognized in a social scene that expressed the same emotion (Kret and de Gelder 2010). This congruency effect was observed in both groups. In Experiment 3 and 4 , violent offenders performed equally well on the congruent trials as the control group, but were extra impaired in recognizing emotions in the incongruent conditions, especially when the context was aggressive. It could be that violent offenders derive different meaning from certain incongruent combinations than controls. In some situations, contexts or postures are more informative for a correct interpretation of emotion and offenders may be more sensitive to these signals. In that sense, it might be unfair to conclude that violent offenders are impaired in recognizing facial expressions in the context of incongruent body cues. For example, a person with a happy posture among fighting people may not signal happiness but some sort of encouragement. If this is the case than it may not be that the offenders are 'wrong', but just that they use different information than controls to deduct what the person is signalling. Another example of how the construction of affective meaning may be different for offenders than controls is the happy faces in combination with angry postures. When people have firsthand experience with fights, a smiling person with an aggressive posture may be extra threatening because it may signal confidence and dominance or a laugh in the face. However, differences in attention to contextual cues between the two groups cannot explain that the effects were particularly strong when the context showed anger. To explain that specificity, we think it is important to keep in mind that the offenders in our study were convicted for extremely violent crimes against other men. They were screened by the staff to include the most aggressive individuals who got into fights a lot in and out of prison. It is well known that a large percentage of violent offenders grew up in a violent environment (Lansford et al. 1995). In such environments, it may have been adaptive to attend to contextual cues and quickly respond and perhaps overreact to cues of threat or misjudge expressions as threatening (better safe than sorry). Earlier studies have suggested an that aggressive populations have a tendency to interpret emotions negatively in aggressive populations (Dodge et al. 1990; Copello and Tata 1990), and the current study supports this as well.

Previous studies have shown the impact of low IQ on crime (Hirschi and Hindelang 1977) and on emotion recognition impairments (Rojahn et al. 1995). Although IQ was not measured in the current study, the control participants were selected from low social economic status groups, most of them had a low education level and some of them were unemployed. We presume that matching on education level may be better than matching on IQ as school has well-known positive effects on social and cognitive skills that maintain in adult life (Hatch et al. 2007). But still, we faced some difficulties here too. Some prisoners were unable to continue their studies in prison but said they would pick this up again when they got out. The motivation not to study is totally different from someone who has the opportunity to study but chooses otherwise. Importantly, the findings in our study cannot be explained by differences in IQ or education level as overall performance was the same between the two groups. The general bias towards angry expressions, (being distracted by them, interpreting other emotions as anger) is different from being good or bad at recognizing anger explicitly. Violent offenders were not better than control subjects in putting a verbal label to an angry expression. In fact, they were sometimes even worse than the control group in labelling angry expressions. Importantly, the major effects are in the more implicit measures such as interpretation biases and contextual effects of anger, and these are independent of intelligence, SES and race and likely related to the aggressive trait of the offenders (Dodge et al. 1990).

One limitation of our study is that various possible factors may have differed between the two groups. Living in a violent environment like a prison may have influenced the results of our study. However, we did conduct some exploratory analyses to investigate whether imprisonment in itself influenced the effects. ${ }^{2}$ Overall, we did not find clear evidence that the observed major findings were influenced by the length of imprisonment. The bias towards aggressive body language does not seem to be increased with imprisonment. In contrast, in Experiment 1, we actually found some

\footnotetext{
${ }^{2}$ In order to keep the focus of the manuscript on the main results, we decided to not report these analyses in the results section. However, the authors can provide the output on request.
} 
indication that the new, least experienced prisoners were more distracted by threatening male body language than the prisoners who already spend half their lives in jail, and this was independent of their younger age. Future studies could include non-aggressive prisoners as a second control group. However, that brings other difficult issues as well, and it is complicated to establish a control group that contains offenders that are of equal intelligence, non-aggressive and with equally long sentence and imprisonment.

Research has shown a strong connection between elevated testosterone levels and increased aggressiveness (Archer 2006) and attention to angry faces (Van Honk et al. 1999; Van Honk et al. 2001). It has been suggested that testosterone may facilitate approach towards signals of dominance challenge (Wirth and Schultheiss 2007). In addition, being exposed to high doses of testosterone prenatally (as measured via digit ratios), correlates with the propensity to engage in aggressive behaviour in adult life (Bailey and Hurd 2005) and predicts sensitivity to threatening faces (Kret and de Dreu 2013). Previous studies found that offenders have smaller digit ratios, that is, a higher prenatal exposure to testosterone and observed a clear link with criminal behaviour (Hanoch et al. 2012). The effects that were observed in the current study can possibly partly be explained by these biological markers. That said, childhood environment may have played an important role as well. Many offenders grew up in violent environments with aggression in their daily routine (Cima et al. 2008; Driessen et al. 2006; Heide and Solomon 2006; Hosser et al. 2007; Kopp et al. 2009; Lansford et al. 1995; Lindberg et al. 2009; Poythress et al. 2006. In turn, individuals exposed to a chronic early adverse history manifest higher levels of trait anger and anger reactivity than individuals who have not been exposed to such a harsh early history (Gardner and Moore 2008). Shahinfar et al. (2001) reported a relation between exposure to violence and social information processing difficulties among incarcerated adolescents.

It is difficult to say where the bias towards threatening body language that we observed in our study originated. But the important finding of our study is that there is such a bias, and this opens doors to therapeutic interventions. Fortunately, learned responses can be modified, especially in the young and non-psychopathic. In recent years, cognitive-behavioural interventions including aggression regulation courses have been developed and implemented in Dutch forensic institutions, and given the declining number of offences, this approach seems successful (CBS 2011: http://statline.cbs.nl). We believe that the new insights from our study may help to improve these interventions.

In summary, our study shows that violent offenders, aggressive men who had committed a violent offence with a male victim, and who have a strong tendency to get involved in fights, have problems with mixed emotional signals with a particular bias towards threatening body language, resulting in lower task performance and incorrect interpretations of happy signals (face or body) when a threatening context (body or scene) is provided.

Acknowledgments This study was supported by grants from NWO (Nederlandse Organisatie voor Wetenschappelijk Onderzoek 400.04081), ERC grant ERC-2011-AdG 295673-EMOBODIES and FP7 TANGO to Beatrice de Gelder and by a grant from the Dr. J.L. Dobberke Stichting, Royal Netherlands Academy of Sciences (KNAW) to Mariska E. Kret. Development of the MacBrain Face Stimulus Set was overseen by N. Tottenham. We would like to thank the anonymous reviewers for their valuable comments. We thank the staff in the prisons, who made this research possible and Inge Henneken-Hordijk for her kind collaboration and for her putting us into contact with the prisons. In addition, we thank S. Dobbelaar for help with data collection and S. Bell for editorial comments.

Open Access This article is distributed under the terms of the Creative Commons Attribution License which permits any use, distribution, and reproduction in any medium, provided the original author(s) and the source are credited.

\section{References}

Archer J (2006) Testosterone and human aggression: an evaluation of the challenge hypothesis. Neurosci Biobehav Rev 30(3): 319-345

Bailey AA, Hurd PL (2005) Finger length ratio (2D:4D) correlates with physical aggression in men but not in women. Biol Psychol 68(3):215-222

Bannerman RL, Milders M, de Gelder B, Sahraie A (2009) Orienting to threat: faster localization of fearful facial expressions and body postures revealed by saccadic eye movements. Proc Biol Sci 276(1662):1635-1641. doi:10.1098/rspb.2008.1744

Becker DV, Kenrick DT, Neuberg SL, Blackwell KC, Smith DM (2007) The confounded nature of angry men and happy women. J Pers Soc Psychol 92:179-190

Cima M, Smeets T, Jelicic M (2008) Self-reported trauma, cortisol levels, and aggression in psychopathic and non-psychopathic prison inmates. Biol Psychol 78(1):75-86. doi:101016/jbiopsy cho200712011

Copello AG, Tata PR (1990) Violent behaviour and interpretative bias: an experimental study of the resolution of ambiguity in violent offenders. Br J Clin Psychol 29:417-428

de Gelder B (2006) Towards the neurobiology of emotional body language. Nat Rev Neurosci 7(3):242-249

de Gelder B, Snyder J, Greve D, Gerard G, Hadjikhani N (2004) Fear fosters flight: A mechanism for fear contagion when perceiving emotion expressed by a whole body. Proc Natl Acad Sci 101(47):16701-16706

de Gelder B, Van den Stock J (2011) The bodily expressive action stimulus test (BEAST) construction and validation of a stimulus basis for measuring perception of whole body expression of emotions. Front Psychol 2:181. doi:103389/fpsyg20110018

de Gelder B, Van den Stock J, Meeren HKM, Sinke CBA, Kret ME, Tamietto M (2010) Standing up for the body Recent progress in uncovering the networks involved in processing bodies and bodily expressions. Neurosci Biobehav Rev 34(4):513-527. doi:1010 16/jneubiorev200910008 
Dodge KA, Price JM, Bachorowski J, Newman JP (1990) Hostile attributional biases in severely aggressive adolescents. J Abnorm Psychol 99(4):385-392. doi:10.1037/0021-843x.99

Driessen M, Schroeder T, Widmann B, von Schonfeld CE, Schneider F (2006) Childhood trauma, psychiatric disorders, and criminal behavior in prisoners in Germany: a comparative study in incarcerated women and men. J Clin Psychiatry 67(10):1486-1492

Fox E, Lester V, Russo R, Bowles RJ, Pichler A, Dutton K (2000) Facial expressions of emotion: are angry faces detected more efficiently? Cogn Emot 14:61-92

Frijda NH (1986) Facial expression processing. In: Jeeves EH, Newcombe MA, Young F, Dordrecht A, Nijhoff M (eds) Aspects of face processing, pp 319-325

Gardner FL, Moore ZE (2008) Understanding clinical anger and violence. The anger avoidance model. Behav Modif 32(6):897-912. doi:101177/0145445508319282

Garson GD (2012) The Literature Review. In: Asheboro NSAP (ed) Available at: http://www.statisticalassociates.com/literaturerevie w.pdf

Gery I, Miljkovitch R, Berthoz S, Soussignan R (2009) Empathy and recognition of facial expressions of emotion in sex offenders, non-sex offenders and normal controls. Psychiatry Res 165(3):252-262. doi:101016/jpsychres200711006

Grèzes J, Pichon S, de Gelder B (2007) Perceiving fear in dynamic body expressions. NeuroImage 35(2):959-967

Hanoch Y, Gummerum M, Rolison J (2012) Second-to-Fourth Digit Ratio and impulsivity: a comparison between offenders and nonoffenders. PLoS ONE 7(10):e47140. doi:10.1371/journal.pone.0047140

Hastings ME, Tangney JP, Stuewig J (2008) Psychopathy and identification of facial expressions of emotion. Personality Individ Differ 44:1474-1483

Hatch SL, Jones PB, Kuh D, Hardy R, Wadsworth ME, Richards M (2007) Childhood cognitive ability and adult mental health in the British 1946 birth cohort. Soc Sci Med 64:2285-2296

Heide KM, Solomon EP (2006) Biology, childhood trauma, and murder: rethinking justice. Int J Law Psychiatry 29(3):220-233

Hirschi T, Hindelang MJ (1977) Intelligence and delinquency: a revisionist review. Am Sociol Rev 42:571-587

Hoaken PN, Allaby DB, Earle J (2007) Executive cognitive functioning and the recognition of facial expressions of emotion in incarcerated violent offenders, non-violent offenders, and controls. Aggress Behav 33(5):412-421

Hosser D, Raddatz S, Windzio M (2007) Child maltreatment, revictimization, and violent behavior. Violence Vict 22(3):318-333

Kopp D, Spitzer C, Kuwert P, Barnow S, Orlob S, Luth H et al (2009) Psychiatric disorders and childhood trauma in prisoners with antisocial personality disorder. Fortschr Neurol Psychiatr 77(3):152-159. doi:101055/s-0028-1109150

Kret ME, de Gelder B (2010) Social context influences recognition of bodily expressions. Exp Brain Res 203(1):169-180. doi:10.1007/ s00221-010-2220-8

Kret ME, de Gelder B (2012) Islamic context influences how emotion is recognized from the eyes. Front Psychol 3(110):1-13. doi:10.3 389/fpsyg.2012.00110

Kret ME, de Dreu CKW (2013) Oxytocin-motivated ally selection is moderated by fetal testosterone exposure and empathic concern. Front Neurosci 7:1. doi:10.3389/fnins.2013.00001

Kret ME, Pichon S, Grèzes J, de Gelder B (2011) Men fear other men most: Sex specific brain activations in perceiving threat from dynamic faces and bodies. An fMRI study. Front Psychol 2:3. doi :10.3389/fpsyg201100003

Kret ME, Stekelenburg JJ, Roelofs K, de Gelder B (2013) Perception of face and body expressions using EMG and gaze measures. Front Psychol. doi:10.3389/fpsyg.2013.00028
Lansford JE, Miller-Johnson S, Berlin LJ, Dodge KA, Bates JE, Pettit GS (1995) Early physical abuse and later violent delinquency: a prospective longitudinal study. Child Maltreatment 12:233-245

Lindberg N, Laajasalo T, Holi M, Putkonen H, Weizmann-Henelius G, Hakkanen-Nyholm H (2009) Psychopathic traits and offender characteristics - a nationwide consecutive sample of homicidal male adolescents. BMC Psychiatry 9:18

Marinkovic K, Halgren E (1998) Human brain potentials related to the emotional expression, repetition, and gender of faces. Psychobiology 26:348-356

Marsh AA, Blair RJ (2008) Deficits in facial affect recognition among antisocial populations: a meta-analysis. Neurosci Biobehav Rev 32(3):454-465. doi:10.1016/j.neubiorev.2007.08.003

Mazurski EJ, Bond NW, Siddle DA, Lovibond PF (1996) Conditioning with facial expressions of emotion: effects of CS sex and age. Psychophysiology 33(4):416-425

McCown WG, Johnson JL, Austin SH (1986) Inability of delinquents to recognize facial affects. J Soc Behav Person 1(4):489-496

Meeren HKM, van Heijnsbergen CC, de Gelder B (2005) Rapid perceptual integration of facial expression and emotional body language. Proc Natl Acad Sci USA 102(45):16518-16523

Öhman A, Dimberg U (1978) Facial expressions as conditioned stimuli for electrodermal responses: a case of "preparedness"? Journal of Personality and Social Psychology 36(11):1251-1258

Poythress NG, Skeem JL, Lilienfeld SO (2006) Associations among early abuse, dissociation, and psychopathy in an offender sample. J Abnorm Psychol 115(2):288-297

Rojahn J, Lederer M, Tassé MJ (1995) Facial emotion recognition by persons with mental retardation: a review of the experimental literature. Res Dev Diffic 16(5):393-414

Sancilio MF, Plumert JM, Hartup WW (1989) Friendship and aggressiveness as determinants of conflict outcomes in middle childhood. Dev Psychol 25(5):812-819

Sato W, Uono S, Matsuura N, Toichi M (2009) Misrecognition of facial expressions in delinquents. Child Adolesc Psychiatry Ment Health 3(1):27. doi:10.1186/1753-2000-3-27

Schupp HT, Öhman A, Junghofer M, Weike AI, Stockburger J, Hamm AO (2004) The facilitated processing of threatening faces: an ERP analysis. Emotion 4(2):189-200

Shahinfar A, Kupersmidt JB, Matza LS (2001) The relation between exposure to violence and social information processing among incarcerated adolescents. J Abnorm Psychol 110(1):136-141

van Honk J, Tuiten A, Verbaten R, van den Hout M, Koppeschaar H, Thijssen J et al (1999) Correlations among salivary testosterone, mood, and selective attention to threat in humans. Horm Behav 36(1):17-24

Van Honk J, Hermans E, Tuiten A, Putman P, Koppeschaar H, Thijssen $\mathrm{J}$ et al (2001) A single administration of testosterone induces cardiac accelerative responses to angry faces in healthy young women. Behav Neurosci 115(1):238-242

Von Borries AKL, Volman I, De Bruijn ERA, Bulten BH, Verkes RJ, Roelofs K (2012) Psychopaths lack the automatic avoidance of social threat: relation to instrumental aggression. Psychiatry Res 200(2-3):761-766. doi:10.1016/j.psychres.2012.06.026

Waas G (1988) Social attributional biases of peer-rejected and aggressive children. Child Dev 59:969-975

Wirth MM, Schultheiss OC (2007) Basal testosterone moderates responses to anger faces in humans. Physiol Behav 90:496-505

Zebrowitz LA, Kikuchi M, Fellous JM (2010) Facial resemblance to emotions: group differences, impression effects, and race stereotypes. J Pers Soc Psychol 98:175-189. doi:10.1037/a0017990 